\title{
What Happened To Our Community Of Practice? The Early Development Of Adult Basic Education In NSW Through The Lens Of Professional Practice Theory
}

\author{
PAMELA OSMOND
}

\begin{abstract}
The field of adult basic education had its genesis as a named field of education in the English speaking world in the mid-1970s, emerging from humanist discourses of social justice and a sociocultural view of literacy. Subsequent decades of its development have involved recurrent and destabilising periods of change with a major and overriding theme being the move away from the humanist philosophy, towards an economically driven, human capital view of literacy, which mirrors the story of a number of other social programs in their trajectory towards the 'new capitalism'. This paper considers the first fifteen years, or genesis, of the field of adult basic education in the state of New South Wales in Australia through official documents and archival material and through the stories from practice told by the teachers. Analysis of these stories using a theory of professional practice knowledge demonstrates the ways in which the early field of professional practice emerged as a product of its particular socio-political climate, and demonstrates also the strong convergence between the public discourses and the professional discourses surrounding the field in this period; a convergence which was progressively weakened in subsequent decades.
\end{abstract}

\section{Introduction}

The 1970s in much of the English-speaking world witnessed a period of general optimism in a new world order and heightened concern for human rights and social justice. This included a concern for opportunities for educationally disadvantaged adults and gave rise

C 2016 Pamela Osmond. This is an Open Access article distributed under the terms of the Creative Commons Attribution 4.0 Unported (CC BY 4.0) License

(https://creativecommons.org/licenses/by/4.0/), allowing third parties to copy and redistribute the material in any medium or format and to remix, transform, and build upon the material for any purpose, even commercially, provided the original work is properly cited and states its license.

Citation: Literacy and Numeracy Studies 2016, 24(2): 4821,

http://dx.doi.org/10.5130/Ins.v24i2.4821 
to the development of adult literacy programs as a recognised and funded sector of many adult education systems (for example, Hamilton and Hillier 2006, Street 1995).

In Australia, the early development of adult literacy programs took slightly different paths in each of the eight states and territories, since adult literacy policy was initially largely a state responsibility, with the federal Australian Government setting overall policy priorities. The study that this paper draws on is a study of the field in NSW which has been subject to its own particular influences, producing state-specific responses to national and international pressures (see Osmond forthcoming).

In Australia, as in other similar countries, this concern for social justice and the humanist philosophy of education which drove the early programs, began to decline by the early 1980s. By this time, the narrative of economic decline had taken control of the public discourse with the result that the newly-minted field of adult literacy became co-opted into the task of economic reform (Wickert et al. 2007, Wickert and Zimmerman 1991). This narrative of literacy development as human capital existed along-side the discourse of human rights for another decade or so, but in the view of many, it has come to displace it almost completely (for example, Lo Bianco 2010).

By 2000, as changes in the socio-political climate which drove the field began to accelerate, Lee and Wickert noted that since there had been no substantial history or systematic analysis of the Australian field written, 'teachers have few places to go to contextualise their own practice' (2000:143-4) adding that 'In order to intervene in and assume control of the future of their field, teachers must develop an understanding of the complexities and inconsistencies that constitute the field' (pp. 140-1). Although some state-based histories have been written (Campbell 2009, Searle 1999), there has previously been no attempt to document a significant history of the adult basic education field in NSW.

The study from which this paper draws begins to address the gap in the telling of the history of adult basic education in NSW by investigating how the discourses and practices in NSW have developed and changed. While the history of the field could be traced through a number of different lenses, for example, policy or learner groups, it is the changes in the educational practice of adult basic education that is of interest in this study. Such a study is timely in the current context of fluidity and volatility of the Vocational Education and Training (VET) context to which the field of adult basic 
education is currently tied; a context which has driven significant change in the educational practices and discourses of the field. It is timely also in that it is important that the memories of professional practice in the field be documented while the institutional memory is still alive in the minds of those professionals who helped to shape those practices.

Thus the study examines the genesis of the field in NSW through the lens of a theory of professional practice knowledge that encompasses the socio-political background against which development of adult basic education practice has taken place. The larger study is titled Adult Basic Education in NSW 1975-2015:

official stories and stories from practice (Osmond forthcoming) The stories from practice and selections of archival and documentary evidence serve to illuminate and illustrate the opportunities and tensions that have characterised this field. An analysis of the development of the field through the lens of the bodies of professional practice knowledge that have characterised it may help to guide present and future practitioners to an understanding of those complexities since it will highlight those aspects of the political and economic background of the practice over which they have no control, and those over which they may be able to exert some agency. Although the study that this paper draws on covers the entire 40 year history of the field in NSW, this paper is concerned only with the first fifteen years of that period; the period which covers the genesis and initial growth of the field, before the transformation of the field began to accelerate, from the early 1990s. Interview data from the study has indicated that this period is of particular interest as practitioners reflected with enthusiasm on a community of practice which was particularly energetic, productive and vibrant, in stark contrast to the current context of practice (Black 2010).

The data is analysed using conceptual resources of professional practice theories which provide a means of understanding the development of and changes in the field. In particular, I adopt Kemmis' (2009) concept of an 'exoskeleton' of practice to describe features such as the social contexts and discourses which are the background to practice. I will trace the exoskeleton of the adult literacy field in NSW in its first fifteen years, followed by an analysis of the body of professional practice knowledge of that period, with 'stories from practice' of practitioners who shared that community of practice. I will briefly discuss the present context of provision and will conclude with a reflection on what this view of the development 
of the field suggests to present and future practitioners as they consider what influence they may be able to exert on the future directions of their practice.

\section{Terminology}

The professional field which is the subject of this study has been identified by a number of different labels over the past 40 years. UNESCO first named and defined a field as adult literacy in the 1950s, in relation to developing nations (Jones 2006, cited in Hamilton 2012:15). This was the label by which it was generally known in the early years in Britain and USA, and adopted in Australia, although its definition was wider than that originally suggested by UNESCO.

The term adult basic education soon came into general use, especially in NSW. It is the term which I favour, largely because of the priority given to 'education' thus connecting it to a wider narrative. It is therefore the term which will be generally used in this study. The term refers to programs which are designed for adults who wish or need to improve their reading, writing and numeracy skills. It is also used to refer to the field in general, its social meanings and implied ideologies and discourses.

The acronym LLN (Language, Literacy, Numeracy) has come into common use more recently, as the discourse of the field has moved from 'education' towards 'training'.

Although the term adult basic education is the chosen terminology for this study, other terms will occasionally be used as appropriate to the discussion of particular discourses or contexts of provision. In general, the terms have similar denotative meanings, although they can be interpreted as code for different discourses.

\section{The study}

The study, Adult Basic Education in NSW 1975-2015: official stories and stories from practice is an historical interpretive study utilising the qualitative methodology of narrative inquiry (Andrews, Squire and Tamboukou 2013, Connelly and Clandinin 1990, Riessman 1993). It is considered that this is an appropriate research approach since it most closely reflects the educational philosophies and theories of literacy that have underpinned the subject of the proposed research; in particular, the social context view of literacy (for example, Hamilton and Hillier 2006). It is ontologically and epistemologically sympathetic to the adult literacy field, valuing, as it 
does, the participant viewpoint. Furthermore, the chosen methodology of narrative inquiry validates the place of the researcher as a participant in the inquiry, a position which I value in the case of my relationship to this study, as a long-term practitioner in the field.

Reflections of adult basic education practices were collected using semi-structured interviews and focus groups with participants selected on the basis of their longevity in the field, evidence of their active engagement in the field and representation across the key periods of change and sites of provision. This paper will draw on interview data from eight of those participants; practitioners who were employed during the early years of the field. All were at the time permanent full-time employees of the department of Technical and Further Education (TAFE) since TAFE NSW was the main provider of adult basic education programs in the foundation stages of the field. Interviewees are not named in this paper, with the exception of Kath White, who holds a particularly significant position as the first adult basic education teacher employed by TAFE NSW and the foundation coordinator of the Adult Literacy Information Office (ALIO) (Johnston, Kelly and Johnston 2001). A desktop audit was also conducted on archival material (such as teaching resources, conference proceedings, newsletters) to add a further dimension to the data.

\section{Professional Practice Knowledge}

The interview and archival data in the study is analysed against a framework of professional practice knowledge: the professional beliefs and practices that are shared by members of a particular community of practice (Lave 1991).

Nicolini draws our attention to the 'broad family of theoretical approaches' (2013:1) which attach themselves to the label of practice theory in an attempt to explain the social world we inhabit. One such approach is Schatzki's (2005) social ontology in which his practice theory is described as consisting of nexuses of practices (or organised human activities) and material arrangements that cohere to form nets of practice-arrangement bundles which in turn can mesh and overlap with other practice-arrangement bundles and form even larger confederation of nets. This understanding of practice resonates well with descriptions of the field of adult basic education and the web of influences brought to bear on its development.

Stephen Kemmis' theory of professional practice (Kemmis 2005a, 2005b, 2009, Kemmis et al. 2014) is similar to Schatzki's in 
its focus on the extra-individual features such as the social contexts and discourses which are the background to practice. Kemmis refers to these as the exo-skeleton of a practice (2009); in Schatzki's terms, the other practice-arrangement bundles in a confederation of nets.

Kemmis' framework is particularly appropriate to the field of adult basic education because, importantly, it highlights the central role and inseparability which the 'exoskeleton' of a practice plays in understanding the community of practice, an understanding which is crucial for an appreciation of the genesis of the field of adult basic education. He draws on a number of theorists including Bourdieu and Foucault to show that 'beyond the individual person of the practitioner, practice is also socially, discursively, culturally and historically formed' (2005a:23). He refers to these extra-individual spaces as

a kind of 'exoskeleton' of arrangements which cause the performance to be realised in particular ways characteristic of this or that profession or this or that location ... These extraindividual features might better be described as the mediating preconditions of practice, arranged in terms of cultures and discourses, social and political structures and dynamics, and material and economic conditions under which a practice is practised. (2009:33)

Kemmis' interpretation of the ways in which members of a community of practice experience these intersubjective spaces through language, in space-time in the material world, and in social relationships will also be drawn on in the examination of the community of practice which is the subject of this paper.

Secondly, Kemmis' framework acknowledges the position of the client as aspect of an understanding of professional practice knowledge - the nature and role of the client being one of the important factors which have characterised the field and its transformation. Although the term 'client' was not one used by the profession in the early days, the data indicates a central focus on the needs and perspectives of the individual students (Lee and Wickert 2000, White 1985). It is indicative of the change in the field that the definition of client has shifted in recent years from student to industry or funding body (for example Black 2010, Yasukawa and Black 2016: vii - ix).

The aspects of professional practice knowledge which are referred to as 'sayings, doings and relatings' (Kemmis et al. 2014:3) also provide a useful framework for the following discussion and 
analysis. This representation of sayings, doings and relatings is mirrored in Higgs et al's taxonomy of

- propositional, theoretical or scientific knowledge;

- professional craft knowledge or knowing how to do something;

- personal knowledge about oneself as a person and in relationship with others'. (cited in Kemmis 2005b:396)

In other words, professional practice knowledge involves knowing cognitively, performatively and affectively.

The range of features which are represented in Kemmis' framework thus provides a useful lens for interpreting participants' reflections on their practice and their professional practice knowledge and to illustrate the ways in which the body of professional practice knowledge came to be created and disseminated amongst the members of the communities of practice. In the first years of the development of the field, participants referred to a rich mix of influences brought to bear on these communities of practice.

\section{ABE's professional practice knowledge in the early years}

The body of professional practice knowledge that emerged in these early years of the profession was, predictably, given its sociopolitical context, grounded in a discourse of individual rights and progressive liberalism. Lee and Wickert (1994:58) report that when teachers were asked about the principles that underpinned their practice, they typically produced lists of principles such as the following:

- student-centred and student-directed learning;

- curriculum based on student needs;

- concern with student as a whole person;

- use student experience as a resource for teaching;

- negotiate learning with student;

- relevant and purposeful learning activities;

- no external assessment;

- learning which develops student independence;

- reflection;

- student as active participant

These firmly held foundation principles of adult basic education reflected humanistic and liberal adult education (Merriam, Caffarella and Baumgartner 2012) and were more or less consistent across place in western democracies such as Australia (Hamilton and Hillier 2006). These principles arose, however, in spite of the fact that there 
was little research and published literature specific to the field (Lee and Wickert 2000, McCormack 2009, McHugh, Nevard and Taylor 2001). McCormack (2009) notes that, particularly in the early, formative years, none of the early practitioners were 'LLN natives; we [were] all "LLN immigrants", (p.9) having learnt our pedagogies in other fields of education.

Interview data from my study serves to highlight the ways in which that body of knowledge came into being; how the 'LLN immigrants' created this robust body of LLN professional practice knowledge.

Whilst this list of principles, or propositional knowledge, was in itself a product of the exo-skeleton of the field, the ways in which teachers became initiated into the community of practice which those principles represent, was also a product of the era. It was an era in which practitioners' professionalism and agency was respected and opportunities were made available for development and expression of that professionalism.

\section{The Exoskeleton of the early years: $1975-1990$}

The beginnings of the field of adult literacy (as it was known then) and the body of professional practice knowledge that developed around it cannot be understood without an understanding of the sociopolitical context that gave rise to it and which can be thought of as part of its 'exoskeleton'.

The development of this new field of adult education in the mid-1970s in Western, developed nations such as Australia had its roots in the vibrant socio-political climate of the late 1960s and early 1970s. The sense that ordinary citizens could contribute to a new world order gave rise to worldwide liberation movements such as the gay rights movement, black power movement and the feminist movement, as a discourse of human rights became a rallying cry for many socially conscious citizens. A general concern for the rights of adults who could not read therefore found fertile ground.

The post-war years in Australia were boom years, with a growth in population from migration, and strong economic growth supported by expansion of industry and commerce. Keynesian economic policies, which informed most western economies in the 1940s to early 1970s, argued for strong fiscal government intervention in the effort to bring about optimum macroeconomic outcomes (Marginson 1997). Australia therefore had the economic ability supported by this economic rationale for a major increase in public spending on 
education and other social programs. 'No social problem seemed beyond solution. A tremendous confidence in government was developing and education was becoming a primary governmental instrument for solving problems' (Marginson 1997:14).

The election of the Whitlam Labor government in Australia in 1972 reflected this optimism with the Whitlam reforms placing a new emphasis on social equality and on the ability and responsibility of governments to address social inequality. This was an important part of the platform on which the Whitlam government was elected, with Whitlam declaring at his policy speech that 'education should be seen as the great instrument for the promotion of equality' (Marginson 1997:46).

A number of watershed government reports from the 1970s provide a further critical aspect of the exoskeleton of the field. The first was The Kangan Report, titled TAFE in Australia: Report on Needs in Technical and Further Education (Kangan 1974). The central recommendation of this report was that the brief of the vocational training system be widened to encompass those who had traditionally been excluded from technical training. This was a highly influential report which foregrounded access and equity concerns and life-long liberal education alongside the technical focus of traditional technical colleges, and changed the name of the sector to Technical and Further Education (TAFE).

The second TAFE in Australia report however, made specific recommendations related to adult literacy and charged state TAFE departments with accepting responsibility for developing provision in the area (Richardson 1975:95). The report also made specific recommendations that

An effective literacy program will almost certainly have to be conducted outside the formal institutional framework. Literacy task forces of special staff are needed to research the problem, including the methodology of teaching, and to develop and provide programs, materials and kits for mobile teaching of small groups. Ways of reaching the adult illiterate will need to be explored, by personal contact through community development officers, social workers, and others, and by advertising literacy programs through the medium of TV. Adult literacy should be regarded by TAFE as a major challenge. The Committee urges State TAFE authorities to regard literacy programs as a high priority in their use of Australian Government funds (1975:96). 
The NSW department of TAFE in particular took up this challenge enthusiastically and within a very short time had appointed a large number of permanent adult basic education teachers. The fact that TAFE NSW had become the major provider of adult basic education programs and the major employer of practitioners in the field, facilitated the resultant integration of adult basic education into the vocational education and training (VET) sector. This did not happen to the same extent in all states in Australia. Zimmerman and Norton write that 'New South Wales provision has been the most comprehensive and secure structurally with adult literacy officers and adult basic education teachers in every TAFE college funded from state revenue.' (Zimmerman and Norton 1990:145)

This recommendation to locate adult basic education policy and programs within the vocational education and training policy area however, was to have a range of crucial implications and foreshadowed the tensions which have characterised the field in the decades to follow (McKenna and Fitzpatrick 2004). It was one of the 'mediating preconditions' (Kemmis 2009:33) which positioned adult basic education in NSW for a decline along with the decline of VET in recent years.

\section{Stories from practice}

\section{'Learning stuff together'}

The data indicates a rich mix of influences which practitioners brought to the field; from their formal tertiary studies in associated disciplines, professional development workshops, professional journals, and informal influence of colleagues.

However, underpinning this, was the sense of agency which the early practitioners felt. Kath White, the first adult literacy teacher appointed in the new Division of Adult Basic Education in TAFE NSW reflected that 'There was an openness in TAFE policy...I had freedom to do whatever I wished with Terry's [Assistant Director] approval and the director's knowledge'. Several other participants reflected nostalgically on the fact that they had the ability to create the field as they went. 'I always did what I had to do. And we were learning all the time. We were learning new stuff. Working in this common thing, and learning stuff together, feeling part of something that was a good thing to be doing.'

The 'learning stuff together' was facilitated in a large way by the establishment of the Adult Literacy Information Office (ALIO) in 
1979. ALIO was established as a referral and resource agency and professional development centre for the field in NSW, loosely following the model of Britain's Adult Literacy Resource Agency. Its first coordinator was Kath White, who had been a significant figure in the lobbying for government funding for its establishment. ALIO became a highly valued part of the exoskeleton of the field. One interviewee said that when she started working in the field 'I didn't know anyone so I went to ALIO'. It became a melting pot for ideas. In the early days, when commercial resources were scarce, ALIO published student-written stories and teacher-developed resources. Workshops were held regularly with sessions delivered by local practitioners or visiting academics such as Canadian Frank Smith and Australian Brian Cambourne, both early proponents of the whole language approach to literacy development. When asked about the influences on their practice, many respondents noted the importance of these professional development sessions at ALIO: 'especially in the early days when ALIO was doing all that stuff there was a lot of really good professional development.'

Although the professional discourses which practitioners espouse and which are represented by the principles listed above are largely of the propositional knowledge category, the workshops and seminars which ALIO developed and many of the resources which they published were of the 'craft knowledge' category (Kemmis 2005b:396).

Sharing examples of craft knowledge, or practical pedagogy became one of the central functions of ALIO, particularly in the early, formative years for the field, and was perhaps the aspect which most excited practitioners. The British publications from the BBC campaign of the 1970s were disseminated through ALIO, as were a number of their own publications. Amongst the early publications was the periodical Broadsheet and a series of Occasional Papers, some of which were aimed at introducing practitioners to the new approach of whole language. The periodical Good Practice in Australian Literacy and Basic Education was a national project, published with federal funding. All of these publications, especially in the early years, were very much concerned with pedagogy, and a desk audit of some of these publications demonstrates that the pedagogy reflects very closely the propositional knowledge or discursive aspects of the field referred to above. For example, the first issue of Good Practice in Australian Literacy and Basic Education was devoted to the theme Student-Centred Learning and contained 
articles which not only provided a rationale for student-centred learning in adult basic education, but examples of the theory in action.

Many of the practitioners interviewed reflected on the importance of these publications in informing their practice. As one interviewee said 'I read omnivorously in the field and of course in those early days we were very influenced, as Kath was, by the system that had begun in England a couple of years earlier so I imbibed a lot of that.' Thus the system that had begun in England a couple of years earlier also formed an important part of the early exoskeleton of the emerging field in Australia. Kath White had visited the UK on a selffunded study tour to document their programs and their use of volunteer tutor programs in particular. In 1978 she wrote that

What has happened in Britain has been influential in the seminal stages of literacy provision in Australia. Although there have been comparable developments, including the use of volunteers, in the USA and Canada, the literature in which they have been reviewed has not been as accessible to Australians as has been the English material. Official British reports and other publications have found their way into library collections and the holdings of the British Council soon after release [in a way that the USA and Canadian materials had not]. (White 1978:17)

\section{Practitioners' own moral judgement}

A number of the interviewees however also spoke of influences on their practice coming from their own moral judgement, or what Higgs et al describe as 'personal knowledge about oneself as a person and in relationship with others' (cited in Kemmis 2005b:396).

When asked how she initially knew what to do with a new student or group of students, Kath related her experience of setting up the first individual Learning Centre in TAFE in 1975, prior to the development of the adult literacy field.

[We] were working on what might be a curriculum; I had planned a mix of phonic and sight word program but as soon as I started to use it with real students I knew it didn't work, because that was not their intention - they wanted to pass a driver's license or they wanted to keep a job and they had an immediate need to be able to read the words for their job so that was all very enlightening once you met the real people.

Another high-school trained teacher related a similar experience from her pre-adult literacy employment, teaching a group of fire 
brigade employees who were being given some extra tuition to help them pass their exams for promotion.

And I am stuck in this terrible situation - I don't actually know what to do, except naively I had some gut feelings so I set it up as ... individual programs for each student ....I did stuff that I didn't even know was part of literacy [teaching]. I'd have them to tell me something and I'd write it down and then I'd get them to read it back. I'd never seen that but it just seemed to be like a sensible thing to do because it would be their words.

This is the reflection-in-action which Kemmis (2005b) refers to as searching for saliences, the drawing on the life-experience of the practitioner reflexively in order to address particular practical problems.

\section{Some anomalies: 'This isn't what I thought adult literacy was about'}

The relationship however, between the field's propositional knowledge (that list of firmly held principles) and the craft knowledge or practical pedagogy in evidence appears to be in some aspects tenuous. The literature questions the extent to which this early discourse was reflected in the pedagogy of the time and suggests that in some respects, it was not (Lee and Wickert 2000; White 1985). This is particularly evident in respect to the Freirean discourse of emancipation which was prominent in the propositional knowledge of the early years.

Brazilian educator Paulo Freire had visited Melbourne as a speaker at a World Council of Churches seminar in 1972. His visit there is partly responsible for the commitment of Victorian literacy workers to adult education as an agent of social change through their community based programs. It is evident though that 'Freire's teachings took much longer to penetrate the other states [including NSW] and with much less effect' (Wickert and Zimmerman 1991:181) although the concepts of emancipation and liberation were prominent in the professional discourse for some decades as part of the propositional knowledge of many practitioners, but with a range of interpretations of what it might mean in affluent Australia.

I read Freire omnivorously in those first years. I said ... 'can we call ourselves Freireans when we live in an affluent society?' We are aiming at emancipation but surely it is a different kind of emancipation. 
Most of the interviewees who were employed in the field from these early years still related to Freire's philosophies. 'One of my underpinning [principles] is still 'liberating, not domesticating'.

It is doubtful however, that Freire would recognise anything of his emancipation ideology in the pedagogy that was actually practiced along-side this discourse. When asked what a typical adult basic education class might have looked like at the time most mentioned individualised programs. Each student had an individual folder in which the teacher would place some pre-prepared, customised materials or worksheets. The student: teacher ratio of the time of $6: 1$ made this possible. The following response was also very typical:

Every single lesson was something current from the newspaper, an interesting story and it's normally something like animals or sharks or those sort of topical things that will get people talking and ... a comprehension exercise with questions after and I remember thinking at the time, this isn't what I thought adult literacy was about - this is almost like school teacher stuff-you give them a worksheet, get them all chatting, relax them, make sure everyone says something and then heads down, and then alright, let's do the real stuff...and I think a lot of people did the same thing.

It is likely that the fact that the program had become the responsibility of TAFE had rendered it institutionalised and as such, Freire's concept of literacy as a political tool was not likely to become a reality in NSW. In spite of the 1975 recommendation to the Australian Government of the Richardson Committee that 'an effective literacy program will almost certainly have to be conducted outside the formal institutional framework' (Richardson 1975:96), classes were conducted in most instances in an institutional framework (with the exception of the volunteer tutor arm of the program). Whilst, in the initial stages, at least, TAFE management was willing to accede to requests for flexibility on many issues because 'our students are different', most of those students were nevertheless in classes in which the social context was irrelevant to their real lives and with fellow students from usually vastly mixed demographic backgrounds. There were some exceptions to this, for example in the case of classes which were set up for Indigenous students. In general however, any discursive suggestions of literacy as a tool for class struggle or even gender based struggle was therefore likely to remain in the realms of rhetoric alone. 


\section{The emergence of a distinct but eclectic $\mathrm{ABE}$ pedagogy}

All of the interviewees spoke warmly of the spirit of sharing in those early years. Ideas and resources were readily shared around: 'We had meetings and talked about good ideas that worked and no one seemed to be 'this is mine'. I think we were very generous and we were accepting as well.' A number of the interviewees who had worked in the western area of Sydney reflected on the fact that the teachers in that region developed an active informal professional development circle, meeting regularly in their own time. 'We did a lot of sharing in those days. We borrowed from each other. We were very collaborative.'

Interviewees agreed on the eclectic nature of the pedagogy in the early days; 'There was no strong theoretical framework, it was pretty much a hotch potch of worksheets, cloze, filling in gaps, trying to adapt newspaper stuff, workbooks, grammar, CVC worksheets. The theory if any was Smith, Goodman, Cambourne, process writing.'

This concept of an eclectic pedagogy would seem a contradiction to the concept of a body of professional practice knowledge, which suggests a shared orthodoxy. There were however, clearly some regulatory forces involved to determine which aspects of pedagogy would be admitted to the hotch potch of shared activities. Theories of adult education, made popular in the early 1970s (for example, Knowles 1973) were prominent in the professional discourse of the new field and seem to be the main filter through which the eclectic pedagogy was screened. One of the interviewees recalled that, as a high-school trained, newly recruited adult literacy teacher, she offered to lead one of the professional development workshops and was firmly taken to task for suggesting ageinappropriate activities. Many of the respondents mentioned adult learning theory when asked what the drivers of their practice were in those early years: 'I think the pedagogy was certainly very heavily influenced by adult learning theory.'

The other teaching approach which quickly came to be filtered out from the shared craft knowledge was the teaching of phonics as a stand-alone or decontextualized activity. Phonics programs were common in the very early years, before the whole language approach became common but quickly it became clear that this was not part of the shared professional practice knowledge: 'We didn't really do any phonics, in fact that was actually quite " $\mathrm{mmm}$, you shouldn't do that". Whole language was promoted for example, through 
professional development programs developed by ALIO and through professional journals.

Interview data and archival material highlight the central position which the client (still called the 'student' in this era) played in the professional practice knowledge of the early years. Genuine attempts were made to turn the rhetoric of participatory education in to practical effect. The early journals of the NSW Adult Literacy Council had a section devoted to student writing, conference programs featured a student stream, with that part of the program organised by students, and the executive committee of the NSW Adult Literacy Council had an ex-officio position for a student member. These may have been tokenistic gestures that touched only a very small proportion of the hundreds of students in programs throughout the state, but they are practical exemplars of the discourse of participatory education which was evident in the education field in general in that era.

In terms of pedagogy also, interviewees mentioned consideration of the needs of the student as being a primary driver of their practice: 'I think it is all about student-centred. That's what it is really about. Student centred was definitely the key because each student came with a different idea of who they were and whether they could do anything.'

It is hard to over-emphasise the impact on the genesis of the field of the exoskeleton which I have outlined. Some of it was tangible, but some was ethereal: 'it was a movement - there is no religious in me, but you just had that bit of fervour because you believed in - don't ask me why. It was empowering'.

This sense of being part of a movement was mentioned by several interviewees and was particular to this era.

'I still have a wonderful sense of the energy and camaraderie that was around in, I guess, the 80 s and very early 90 s as adult literacy just burgeoned as a movement and you had a sense that you were building this fantastic, useful, powerful, (sorry, I'm getting a bit carried away)... It was fantastic.'

\section{The present context}

By the late 1980s the public discourse had changed and greater government involvement weakened practitioners' sense of agency to create their field, or even to respond to students' needs as they saw them. The public discourse became centred around employmentrelated literacy, literacy as human capital. The client ceased to be the 
student and the government or accrediting body was now the demanding client. With this came a regime of public management, compliance measures and an 'audit culture' (Black 2010, Lo Bianco 1997). The creative community of practice of the earlier era, with its discourse of student centred learning became colonised by this audit culture. This was a constant theme in the interview data, with consensus amongst interviewees that it is perhaps time to return adult basic education provision to its former ideals as a social justice project.

\section{Conclusions}

This article has traced the genesis of the field of adult basic education in NSW through the lens of a theory of professional practice knowledge in order to distinguish those aspects of the field which are amenable to influence for change and those that are likely to be an intractable aspect of the new capitalism. Much of what interviewees reflected on as being central to the early field could be seen to fit into what Kemmis refers to as the exoskeleton of the field which includes the socio-political context and discourses of the era. The public discourse of liberal humanism of the 1970s and 80s promoted generous government funded opportunities for dissemination of ideas amongst the developing community of practice. It provided the context for provision of formal professional development opportunities, the growth of professional journals and newsletters, and even provided the context for the informal opportunities for exchange of ideas which interviewees refer to. Thus a vital body of shared professional practice knowledge was generated in the first fifteen years of the field.

Kemmis' theory of professional knowledge also provides a framework against which to discuss the anomalies in practitioners' reflections, such as that between some aspects of the shared propositional knowledge, and the practical pedagogy or craft knowledge evident at the time. It also accounts for practitioners' own in-the-head knowledge involving their own moral judgement; an aspect of professional practice knowledge which may not be dependent on the socio-political context or exoskeleton of the field.

The challenge of future practitioners may be to use this moral judgement to attempt to regain some of the lost sense of professional agency and to find a new site of practice; a new exoskeleton in which to create a new body of professional practice knowledge which is again responsive to student needs. 
The interview data recalled an energetic community of practice, creating a distinct body of professional practice knowledge and adult basic education pedagogy which mirrored the more liberal public discourses of the era. The humanist adult education principle of student-centredness was central to both the public and professional discourse. Current practitioners reflect on this wistfully. They regard much of that discourse as potentially relevant still, in this more hostile environment of the 'new capitalism' where public discourses centred on human capital assume priority in sites of publically funded adult basic education provision.

\section{References}

Andrews, M, Squire, C and Tamboukou, M, eds, (2013) Doing Narrative Research, Sage, London.

Black, S. 2010, 'Working the Interstices: Adult basic education teachers respond to the audit culture', Literacy and Numeracy Studies, vol 18, no 2, pp 6 - 25. doi: https://doi.org/10.5130/lns.v18i2.1895

Campbell, B (2009) Reading the Fine Print - A history of the Victorian Adult Literacy and Basic Education Council (VALBEC) 1978 2008, Victorian Adult Literacy and Basic Education Council, Springvale South.

Connelly, F and Clandinin, J (1990) Stories of Experience and Narrative Inquiry, Educational Researcher, vol 19, no 2, pp 2 14. doi: https://doi.org/10.3102/0013189X019005002

Hamilton, M (2012) Adult Literacy in a Global Marketplace, Fine Print, A Journal of Adult English Language and Literacy Education, vol 35, no 2, pp 14 - 8.

Hamilton, M and Hillier, Y (2006) Changing Faces of Adult Literacy, Language and Numeracy: A critical history, Trentham Books, Stoke on Trent.

Johnston, B, Kelly, S and Johnston, K (2001) The Rise and Fall of the NSW Adult Literacy and Information Office, NSW ALNARC, Sydney.

Kangan, MC (1974) TAFE in Australia: Report on needs in Technical and Further Education, AGPS, Canberra.

Kemmis, S (2005a) Is Mathematics Education a Practice? Mathematics teaching? in Goos, M, Kaynes, C and Brown, R, eds, Fourth International Mathematics Education and Society Conference, Griffith University, Gold Coast, Qld, pp 19 - 38. 
Kemmis, S (2005b) Knowing Practice: Searching for saliences, Pedagogy, Culture and Society, vol 13, no 3, pp 391 - 426. doi: https://doi.org/10.1080/14681360500200235

Kemmis, S (2009) Understanding Professional Practice: A synoptic framework, in Green, B, ed, Understanding and Researching Professional Practice, Sense, Rotterdam, pp 19 - 38.

Kemmis, S, Wilkinson, J, Edwards-Groves, C, Hardy, I, Grootenboer, P and Bristol, L (2014) Changing Practices, Changing Education, Springer, Singapore. doi: https://doi.org/10.1007/978-981-4560$\underline{47-4}$

Knowles, M (1973) The Adult Learner: A neglected species, Gulf, Houston.

Lave, J (1991) Situating Learning in Communities of Practice, Perspectives on Socially Shared Cognition, vol 2, pp 63-82. doi: https://doi.org/10.1037/10096-003

Lee, A and Wickert, R (1994) Deconstructing Adult Literacy Teaching, Open Letter, vol 5, no 1, pp 55-68.

Lee, A and Wickert, R (2000) Reading the Discourses of Adult Basic Education Teaching, in Foley, G, ed, Understanding Adult Education and Training, Allen and Unwin, Sydney, pp 140 - 52.

Lo Bianco, J (1997) Policy Proliferation: Can literacy cope?, Fine Print: A Journal of Adult English Language and Literacy Education, vol 20, no 1, pp 3 - 11.

Lo Bianco, J (2010) Multicultural Education in Australia: Evolution, compromise and contest, paper presented to the IALEI, Singapore, retrieved Feb 16, 2014, http://www.intlalliance.org/fileadmin/user_upload/documents/Co nference_2010/NP-AU.pdf.

Marginson, S (1997) Educating Australia - Government, Economy and Citizen Since 1960, Cambridge University Press, Cambridge. doi: https://doi.org/10.1017/CBO9781139166966

McCormack, R (2009) Groping Towards Our Field, Fine Print: A Journal of Adult English Language and Literacy Education,vol 32, no 3, pp 9 - 11.

McHugh, M, Nevard, J and Taylor, A (2001) The melody changes but the dance goes on - tracking adult literacy education in Western Australia from 'learning for life' to 'lifelong learning': policy impacts on practice 1973-1999, in Lo Bianco, J and Wickert, R, eds, Australian Policy Activism in Language and Literacy, Language Australia, Melbourne, pp 181 - 202. 
McKenna, R and Fitzpatrick, L (2004) Building Sustainable Adult Literacy Provision - A review of international trends in adult literacy policy and programs, NCVER, Adelaide.

Merriam, S, Caffarella, R and Baumgartner, L (2012) Learning in Adulthood: A comprehensive guide, Jossey-Bass, San Francisco.

Nicolini, D (2013) Practice Theory, Work, and Organisation, Oxford University Press, Oxford.

Richardson, EC (1975) TAFE in Australia: Second report on needs in technical and further education, Canberra.

Riessman, C (1993) Narrative Analysis, Sage, London.

Schatzki, T (2005) Peripheral Vision: The sites of organisations, Organization Studies, vol 26, no 3, pp 465 - 84. doi: https://doi.org/10.1177/0170840605050876

Searle, J (1999) An Unsung Band of Heroes: A history of adult literacy in Queensland 1970 - 1995, PhD thesis, Griffith University, Queensland.

Street, B (1995) Adult literacy in the United Kingdom - A history of research and practice, National Centre on Adult Literacy, Philadelphia.

White, K (1978) Voluntarism and Bureaucracy: Trends in the utilisation of volunteers in adult literacy programmes in New

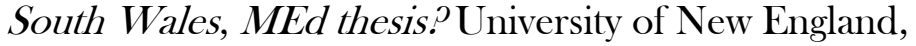
Armidale, Australia.

White, K (1985) Influences on Adult Literacy Practice in Australia, paper presented to the Adult Literacy and Community Development Workshop, August 19 - 25, 1985, Armidale, Australia.

Wickert, R, Searle, J, Marr, B and Johnston, B (2007) Opportunities, Transitions and Risks: Perspectives on adult literacy and numeracy development in Australia, Review of Adult Learning and Literacy, vol 7, no 8, pp 245 - 84.

Wickert, R and Zimmerman, J (1991) Adult Basic Education in Australia: Questions of integrity, in Tennant, M, ed, Adult and Continuing Education in Australia: Issues and practices, Routledge, London, pp 175 - 206.

Yasukawa, K and Black, S, eds, (2016) Beyond Economic Interests: Critical perspectives on adult literacy and numeracy in a globalised world, Sense, Rotterdam.

Zimmerman, J and Norton, M (1990) The Challenges for Adult Literacy in Australia, in D'Cruz, J and Langford, P, eds, Issues in 
Australian Education, Longman Cheshire, Melbourne, pp 144 68. 